\title{
Mini-Review
}

Fetal Diagnosis ant Therapy

\section{The Aortic Isthmus: A Significant yet Underexplored Watershed of the Fetal Circulation}

\author{
Dominique Tynan $^{a}$ Jennifer Alphonse ${ }^{b, c}$ Amanda Henry ${ }^{a-d}$ Alec W. Welsh ${ }^{a-c}$ \\ ${ }^{a}$ Faculty of Medicine, University of New South Wales, Kensington, N.S.W., 'bchool of Women's and Children's \\ Health, University of New South Wales Medicine, and 'Department of Maternal-Fetal Medicine, Royal Hospital for \\ Women, Randwick, N.S.W., and 'Women's and Children's Health, St George Hospital, Kogarah, N.S.W., Australia
}

\section{Key Words}

Aortic isthmus · Watershed $\cdot$ Isthmic flow index $\cdot$ Isthmic systolic index $\cdot$ Intrauterine growth restriction

\begin{abstract}
The aortic isthmus (Aol) is a unique fetal watershed with a waveform reflecting its complex haemodynamic physiology. The systolic component represents left and right ventricular systolic ejection, and the diastolic component represents comparative downstream vascular impedance between the brachiocephalic and subdiaphragmatic fetal circulations. Several indices have been devised to quantify different components of the waveform, including the pulsatility index, resistance index, isthmic flow index, and recently the isthmic systolic index. There have been promising preliminary studies applying these indices to both cardiac (congenital) and extracardiac pathologies, including intrauterine growth restriction and twin-twin transfusion syndrome. However, the waveform's multifactorial origin has proven to be challenging, and the difficulty in separating various components of the waveform could explain that Aol evaluation does not have a clear clinical utility. Further research is underway to realise the full potential of this vessel in fetal cardiac and haemodynamically compromised pathological
\end{abstract}

conditions. In this review article we outline the physiological origin of this Doppler waveform, describe in detail the various published indices, summarise the published literature to date, and finally outline potential future research and hopefully clinical applications.

(c) 2016 S. Karger AG, Base

\section{Introduction}

The aortic isthmus (AoI) is anatomically located between the origin of the left subclavian artery and the aortic end of the ductus arteriosus (DA) [1-3] (fig. 1). There are three points in the fetal circulation that have been described as 'watersheds', suggesting they represent a meeting point between two vascular systems [4]. These are the left portal vein, the foramen ovale with its crista dividens, and the AoI [4]. Watersheds are of particular interest as their velocity waveform reflects both ventricular contributions to flow and/or the difference in downstream vascular impedance between circulations $[1,4]$. In particular they provide significant information about fetal haemodynamic compromise and structural pathology. Because of the location of the AoI, it may also be described as the only 'arterial shunt' in the fetal circulation with the pos-

\section{KARGER}

E-Mail karger@karger.com

www.karger.com/fdt
(C) 2016 S. Karger AG, Basel

$1015-3837 / 16 / 0402-0081 \$ 39.50 / 0$
Prof. Alec W. Welsh

University of New South Wales

Royal Hospital for Women

Barker St., 2031 Randwick, NSW (Australia)

E-Mail alec.welsh@unsw.edu.au 


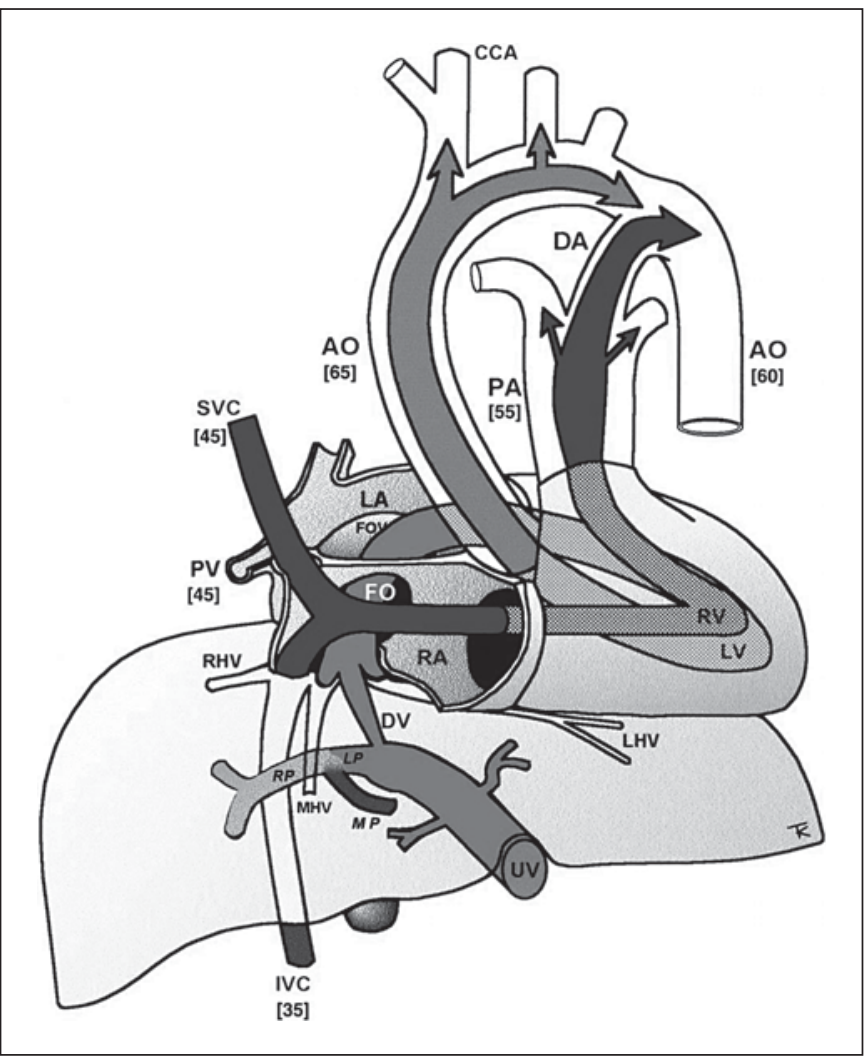

Fig. 1. The fetal circulation, with the AoI indicated by the arrow [4]. AO = Aorta; CCA = common carotid artery; LA = left aorta; $\mathrm{RA}=$ right aorta; $\mathrm{LP}=$ left pulmonary artery; $\mathrm{MP}=$ main pulmonary artery; $\mathrm{RP}=$ right pulmonary artery; $\mathrm{FO}=$ foramen ovale; $\mathrm{PV}=$ portal vein; $\mathrm{LHV}=$ left hepatic vein; $\mathrm{MHV}=$ middle hepatic vein; $\mathrm{RHV}=$ right hepatic vein; IVC = inferior vena cava; UV = umbilical vein.

sibility for blood to be directed from its original destination towards a circuit with lesser resistance $[1,2,4]$. These circuits include the brachiocephalic or the placental and subdiaphragmatic circulation, depending on the downstream impedance of each $[1,2,4]$.

\section{Visualisation}

The AoI can be viewed using either of two sonographic planes. These are the traditional longitudinal aortic arch (LAA) view, where the sonographic gate is placed a few millimetres beyond the origin of the left subclavian artery, and the cross-sectional three vessels and trachea $(3 \mathrm{VT})$ view, where the sonographic gate is placed just prior to the convergence of the AoI on the DA (fig. 2) [5-7]. To obtain adequate AoI views, colour-directed pulse- wave Doppler is recommended for identification of the relevant vessels. Velocity waveforms should be recorded during fetal quiescence with the angle of insonation kept close to $0^{\circ}$ and no more than $30^{\circ}$ [2]. The gate size should be modified to accommodate the linear growth of the AoI diameter with gestation whilst avoiding recording signals from adjacent vessels [2].

The $3 \mathrm{VT}$ view is thought to be faster to obtain and less technically challenging to visualise as it often forms part of routine heart examinations, as opposed to the LAA view $[5,8,9]$. The largest study (361 normal singleton fetuses) comparing $3 \mathrm{VT}$ and LAA views found acquisition rates for the pulsatility index (PI) of 93.9 versus $72.9 \%$ for the $3 \mathrm{VT}$ and LAA, respectively [9]. However, while visualisation of the AoI in the $3 \mathrm{VT}$ view may be easier, many clinicians find accurate sonographic gate placement challenging in this view, due to the increased likelihood of inadvertently recording the transverse aortic arch or DA rather than the isthmus $[2,10]$. The $3 \mathrm{VT}$ view cannot simultaneously view the head and neck vessels and the distinctive $\mathrm{V}$ shape formed by the aortic arch and ductal arch that is used to guide gate placement; thus visualisation relies upon recognition of the characteristics of the AoI waveform. For this reason, our group prefers the LAA view for sonographic gate placement as the left subclavian artery (proximal limit of the AoI) and aortic arch can be simultaneously visualised to ensure accurate differentiation of the AoI and DA (fig. 3). We find the LAA AoI view to be more readily obtainable than the $3 \mathrm{VT}$ view when the fetus is in the prone position. Additionally, only in the LAA view is a narrow incisura and small reversal of flow during systole visualised after 25 weeks' gestation [11].

\section{Physiology}

The fetal circulation comprises two parallel circuits with two ventricular pumps perfusing the one systemic circulation [1]. The left ventricle (LV) perfuses the coronary and brachiocephalic circulations, while the right ventricle (RV) perfuses the subdiaphragmatic circulation and placenta $[1,2,4]$. Due to this parallel arrangement, it is important to have tools to assess the LV and the RV separately $[12,13]$. In normal fetal development the RV is predominant, with a mean cardiac output (CO) 13$25 \%$ greater than that of the LV [4]. In certain pathological conditions where the fetus is haemodynamically compromised, such as in intrauterine growth restriction (IUGR), it is thought that the RV is affected earlier and to a greater degree $[3,12]$. This RV strain is demonstrated 
Fig. 2. AoI showing identifying landmarks (arrows) and cursor placement (asterisks). a LAA view. b 3 VT view. SVC = Superior vena cava; $\mathrm{Ao}=$ aorta; $\mathrm{PA}=$ pulmonary artery; $\mathrm{T}=$ trachea.

Fig. 3. Longitudinal view of the aortic arch (a) and ductal arch (b), with the asterisk in a indicating the isthmus and the asterisk in b indicating the pulmonary ductal arch (left) and corresponding pulse-wave waveforms (right).
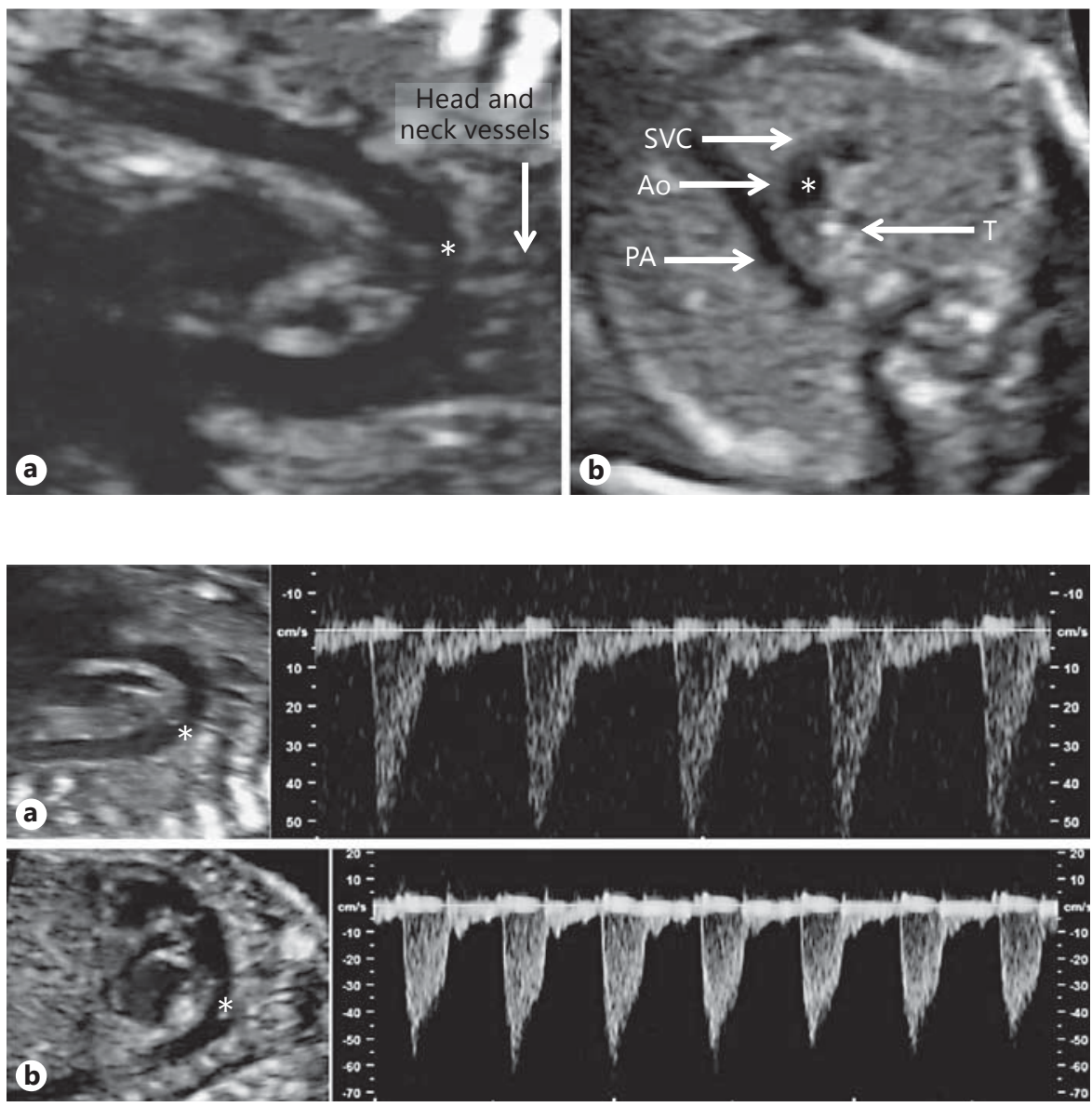

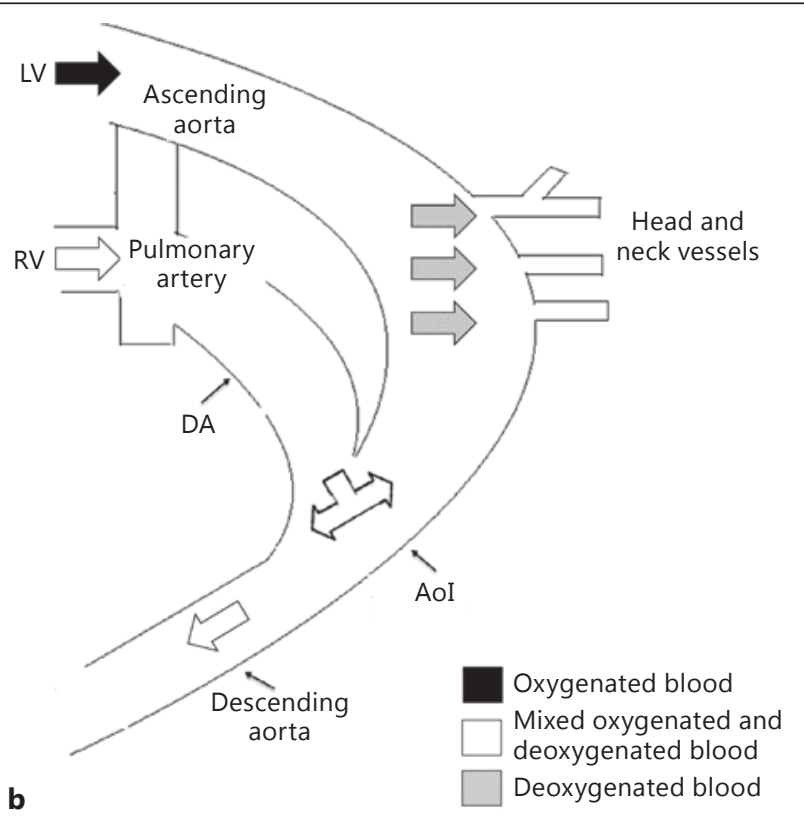

Fig. 4. Schematic representations of the AoI LAA view indicating the direction of blood flow in a normally grown fetus (a) and with severe growth restriction $(\mathbf{b})$. 


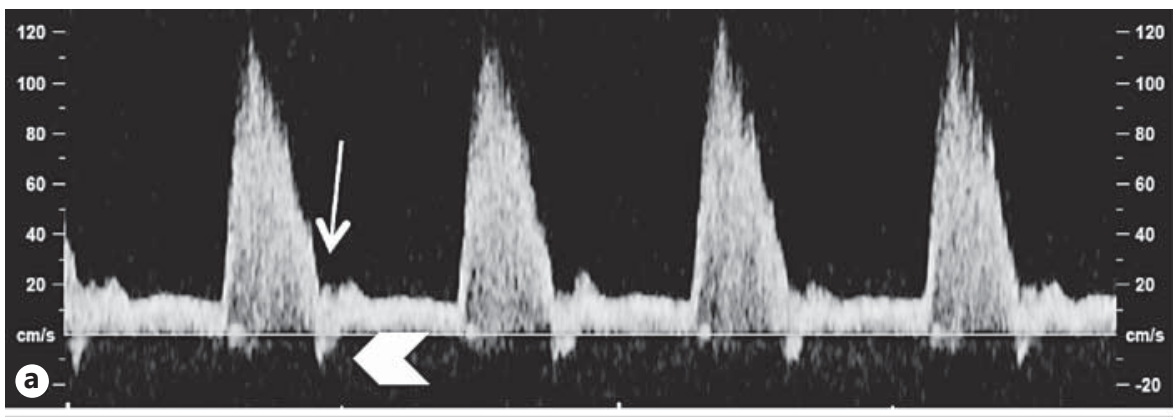

Fig. 5. Typical normal (a) and abnormal (b) AoI Doppler flow velocity waveforms in the 3 rd trimester. The arrows $(\mathbf{a}, \mathbf{b})$ point to the nadir, and the chevron (a) points to the brief retrograde flow at the end of systole. In b AoI flow is reversed in late systole and net flow is retrograde in diastole [2].

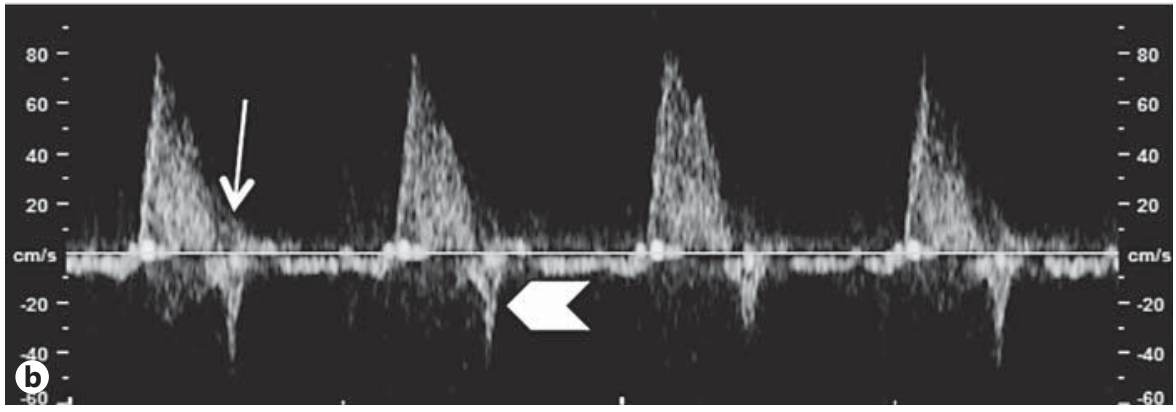

by earlier dilation, hypertrophy, and dysfunction compared to changes in the LV [3].

The anatomical location of the AoI means the LV and $\mathrm{RV}$ contribute to AoI flow in opposing directions (fig. 4) $[1,2]$. LV ejection is responsible for systolic anterograde flow through the AoI, whereas the RV is responsible for systolic retrograde flow [14]. The direction of systolic AoI blood flow is thus determined by the comparative LV and RV stroke volumes along with the downstream vascular impedances [1]. In diastole, when the two semilunar valves are closed, the direction of AoI blood flow is determined purely by the balance of downstream vascular impedance in the brachiocephalic and placental and subdiaphragmatic circulation [15]. The AoI waveform can therefore be seen as the product of a complex interaction between (a) LV and RV ejection and (b) brachiocephalic plus placental and subdiaphragmatic vascular impedance. The numerous inputs that shape the AoI waveform distinguish it as a vessel of interest whilst making its interpretation difficult.

The AoI has a characteristic Doppler velocity waveform. Firstly, there is a quick systolic upstroke ranging between 30 and $100 \mathrm{~cm} / \mathrm{s}$ from 11 weeks' gestation to term that gradually decelerates during gestation [2]. By 25 weeks a narrow incisura then appears which suggests a progressive reduction in AoI antegrade flow (fig. 5) [2, 16]. A brief reversal of systolic flow is visible from 28 weeks' gestation $[1,2]$ that has been identified as the nadir of systole [14]. A previous study questioned whether this could be an artefact [11], but the systolic nadir is now thought to be physiologically accurate.

The AoI waveform changes slightly throughout gestation, reflecting both the physiological evolution of fetal ventricular function and changes in peripheral vascular impedance with gestation. In normal fetuses antegrade flow is present in the first half of pregnancy in both systole and diastole of the AoI waveform due to low placental vascular impedance. The gradual deceleration of the systolic upstroke with a brief reversal of flow may be due to increasing $\mathrm{RV}$ dominance, coupled with the rise in placental impedance that occurs with gestation $[1,14,15]$. However, a large cross-sectional study (458 fetuses) found no correlation between AoI PI and umbilical artery (UA) PI, suggesting rather that they could be considered independent factors for fetal surveillance [11]. The reduction in cerebrovascular resistance that occurs during normal gestation, as evidenced by the progressive decrease in the middle cerebral artery (MCA) resistance indices, may also contribute to these changes that occur later in gestation, due to the rise in RV preload and output being directed via the DA $[11,14]$.

\section{Quantification of the Aol}

A number of cardiac indices have been developed in an attempt to quantify flow and characterise resistance to flow in the AoI, including those used for other vessels as well as others unique to the AoI.
Tynan/Alphonse/Henry/Welsh 
Table 1. Mean values (SD) of the AoI PI or regression equations as a function of gestational age (GA) in completed weeks in both LAA and 3VT views in normal singleton pregnancies and normal twin pregnancies from the published literature until 2015

\begin{tabular}{|c|c|c|c|c|c|c|c|}
\hline Study [Ref.], year & $\begin{array}{l}\text { Fetuses, } \\
\mathrm{n}\end{array}$ & $\begin{array}{l}\text { Cases from } \\
\text { LAA view }\end{array}$ & $\begin{array}{l}\text { Cases from } \\
3 \text { VT view }\end{array}$ & $\begin{array}{l}\text { GA, } \\
\text { weeks }\end{array}$ & PI or regression equation & $\begin{array}{l}\text { LAA view: } \\
\text { PI or regression equation }\end{array}$ & $\begin{array}{l}\text { 3VT view: } \\
\text { PI or regression equation }\end{array}$ \\
\hline Gámez et al. [9], 2015 & 361 & 263 & 339 & $19-36$ & - & $2.072+(0.014 \times \mathrm{GA})^{\mathrm{a}}$ & $2.169+(0.016 \times \mathrm{GA})^{\mathrm{a}}$ \\
\hline Gámez et al. [9], 2015 & $182^{\mathrm{b}}$ & 94 & 146 & $19-36$ & - & $\begin{array}{l}5.112+(-0.242 \times \mathrm{GA})+ \\
\left(0.005 \times \mathrm{GA}^{2}\right)^{\mathrm{a}}\end{array}$ & $2.006+(0.017 \times \mathrm{GA})^{\mathrm{a}}$ \\
\hline Del Río et al. [11], 2006 & 458 & 130 & 328 & $19-37$ & $2.2562+(0.0153 \times \mathrm{GA})^{\mathrm{a}}$ & - & - \\
\hline Thanasuan et al. [18], 2014 & 240 & 209 & 31 & $24-38$ & $1.74+(0.02 \times \mathrm{GA})^{\mathrm{a}}$ & - & - \\
\hline \multicolumn{8}{|l|}{ Cruz-Martinez et al. [50], } \\
\hline 2011 & 178 & - & - & $37+$ & 2.87 & - & - \\
\hline Kennelly et al. [15], 2012 & 72 & 25 & 25 & $18-38$ & - & $2.72(0.31)$ & $2.78(0.28)$ \\
\hline Del Río et al. [5], 2005 & 40 & 40 & 40 & $24-36$ & - & $2.52(0.33)$ & $2.55(0.30)$ \\
\hline Vimpeli et al. [16], 2009 & 143 & - & - & $11-20$ & $2.4-2.6^{\mathrm{a}}$ & - & - \\
\hline Karakus et al. [19], 2015 & 71 & - & - & $26-40$ & $1.9(0.4)$ & - & - \\
\hline
\end{tabular}

${ }^{a}$ Weekly gestational age reference range tables published in the article. ${ }^{\mathrm{b}}$ Twin cohort.

Table 2. Mean values (SD) of the AoI RI or regression equations as a function of gestational age (GA) in completed weeks in both LAA and $3 \mathrm{VT}$ views in normal singleton pregnancies in the published literature until 2015

\begin{tabular}{|c|c|c|c|c|c|}
\hline Study [Ref.], year & Fetuses, $\mathrm{n}$ & GA, weeks & RI or regression equation & LAA view: RI & 3VT view: RI \\
\hline Del Río et al. [11], 2006 & 458 & $19-37$ & $0.8984+(0.0007 \times \mathrm{GA})$ & - & - \\
\hline Thanasuan et al. [18], 2014 & 240 & $24-38$ & $0.87(0.04)$ & - & - \\
\hline Del Río et al. [5], 2005 & 40 & $24-36$ & - & $0.91(0.02)$ & $0.90(0.03)$ \\
\hline Vimpeli et al. [16], 2009 & 143 & $11-20$ & $0.91-0.94$ & - & - \\
\hline Karakus et al. [19], 2015 & 71 & $26-40$ & $0.83(0.2)$ & - & - \\
\hline
\end{tabular}

\section{Volume Flow Measurements}

AoI volume blood flow $\left(\mathrm{Q}_{\mathrm{ai}}\right)$ has been measured and calculated as $\mathrm{Q}_{\mathrm{ai}}(\mathrm{ml} / \mathrm{min})=\pi \times(\text { AoI diameter } / 2)^{2} \times$ velocity time integral $(\mathrm{VTI}) \times$ heart rate $\times 60$ [16]. A single study has established reference ranges for AoI $\mathrm{Q}_{\mathrm{ai}}$, longitudinally evaluating 143 fetuses from 11 to 20 weeks to estimate the fraction of fetal $\mathrm{CO}$ distributed to the upper body [16]. The success rate of acquiring data for $\mathrm{Q}_{\mathrm{ai}}$ calculation was only $33 \%$ at $11-13^{+6}$ weeks, $62 \%$ at $14-16^{+6}$ weeks, and $83 \%$ at $17-20$ weeks. Whilst AoI volume blood flow quantification is technically feasible, its use is precluded by the potential calculation inaccuracies introduced by its relatively small diameter $[5,16]$.

\section{PI and Resistance Index}

The AoI PI and resistance index (RI) are measured as an average of at least three clear consecutive waveforms to determine the peak systolic velocity (PSV), end-diastolic velocity (EDV), and time-averaged maximum velocities (TAMXV), and they are calculated as follows: $\mathrm{PI}=(\mathrm{PSV}-\mathrm{EDV}) / \mathrm{TAMXV}$ and $\mathrm{RI}=(\mathrm{PSV}-\mathrm{EDV}) / \mathrm{PSV}$
[11]. These indices commonly used in fetal medicine assess both systolic and diastolic components of the waveform with particular sensitivity to downstream impedances that influence AoI flow [10]. In severely growthrestricted fetuses with retrograde net flow, AoI PI values become abnormally high $[11,17]$.

To the best of our knowledge, three gestational age reference ranges have been published for the PI in uncomplicated singleton fetuses, and one reference range in twins $[9,11,18]$. Five studies have also published mean PI values in a control group of uncomplicated singleton fetuses $[5,6,15,16,19]$. In all studies PI values were obtained using both the $3 \mathrm{VT}$ and the LAA view, with three of the studies differentiating PI results from each view. Table 1 illustrates that most studies have found average PI of 2.0-3.0, with gradual increases throughout gestation [19]. While PI values from the LAA view are slightly lower than those obtained from the $3 \mathrm{VT}$ view (table 1), all studies found this not to be significant. The largest study comparing PI values obtained from the $3 \mathrm{VT}$ view with values obtained from the LAA view found no statistical 


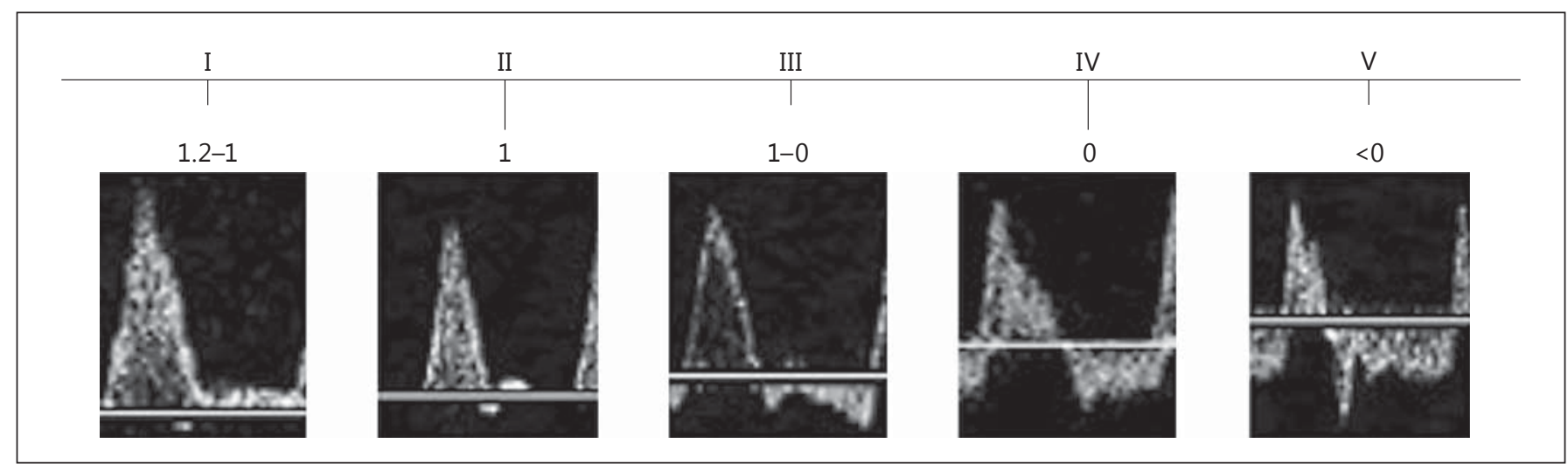

Fig. 6. Examples of AoI Doppler blood flow velocity waveforms in intrauterine growth-restricted fetuses, with severity graded in roman numerals and IFI values in Arabic figures [38].

Table 3. Mean values (SD) of the IFI or regression equations as a function of gestational age (GA) in completed weeks in normal singleton pregnancies in the published literature until 2015

\begin{tabular}{lclll}
\hline Study [Ref.], year & Fetuses, $\mathrm{n}$ & View used & GA, weeks & IFI or regression equation \\
\hline Ruskamp et al. [20], 2003 & 111 & LAA & $18-39$ & $1.41-(0.0047 \times \mathrm{GA})$ \\
Zielinsky et al. [21], 2011 & 23 & LAA, 3VT & $25-39$ & $1.315(0.069)$ \\
Karakus et al. [19], 2015 & 71 & LAA, 3VT & $26-40$ & $1.19(0.1)$ \\
\hline
\end{tabular}

difference and agreement of the values as 'fair' for singleton fetuses and 'good' in twins [9]. Other studies also found good agreement between measurements taken from the two views $[5,8]$.

Two gestational age reference ranges have been established for RI $[11,18]$, and three studies have published mean RI values in a control group of uncomplicated singleton fetuses [5, 16, 19] (table 2). Apart from the study by Karakus et al. [19] (which also found lower mean PI than other reference studies), published RI values are similar, with no significant difference with regard to whether they are obtained from the LAA or the 3VT view.

\section{Isthmic Flow Index}

The isthmic flow index (IFI) is a semi-quantitative measure calculated as IFI = (systolic VTI + diastolic VTI)/systolic VTI [20]. Rather than creating an absolute value, the IFI is described as one of five types (fig. 6): type I: IFI $>1$, flow is antegrade in both systole and diastole; type II: IFI = 1, absence of diastolic flow; type III: IFI $0-1$, diastolic flow is reversed, but net flow is still antegrade; type IV: IFI $=0$, antegrade and retrograde flows are equal, and type V: IFI $<0$, when the net flow is retrograde [20]. Only one normal singleton gestational age range has been established for the
IFI using 111 fetuses, and two studies have published mean IFI values for control groups of 23 fetuses and 71 fetuses, respectively (table 3) [19-21]. While the control group of 23 fetuses showed good concordance of the mean raw IFI values with the normal-range study [20,21], Karakus et al. [19] reported significantly lower IFI values, which was the same finding as for their PI and RI values.

The IFI has not been widely adopted amongst clinicians as it requires manual classification and provides no comparative information for fetuses with predominately antegrade flow [11]. The argument for using VTI-related indices as opposed to TAMXV-related indices was based on an assumption that they provided more information on the amount or volume of blood flow and its direction [20]. However, TAMXV-related indices are equally sensitive to changes in net blood flow, as the PI denominator measures the size of the reverse flow component; VTI indices do not appear to be of added benefit.

\section{Isthmic Systolic Index}

The isthmic systolic index (ISI) has recently been proposed to measure the comparative ventricular contributions to the AoI Doppler flow velocity waveform [14], calculated from the ratio of Ns/Ps, where Ps refers to the PSV
86

Fetal Diagn Ther 2016;40:81-93 DOI: $10.1159 / 000446942$
Tynan/Alphonse/Henry/Welsh 
and Ns refers to the end-systolic velocity or systolic nadir [14]. A single gestational age range has been published in a cross-sectional study of 261 normal fetuses, demonstrating a widening gap throughout gestation between the Ps and Ns, the ISI decreasing and the RV becoming predominant with end-systolic deceleration and eventual reversed AoI systolic flow [14]. There was high interobserver agreement, with a proposal that its use in pathology may help stratify unilateral fetal cardiac dysfunction and morbidity risk [14].

Our own research team has documented the difference between the left and the right myocardial performance index (MPI) as 'Delta-MPI' [13], though in subsequent research we were unable to find a correlation between the unilateral cardiac indices, Delta-MPI, and AoI ISI. This is likely to reflect the influence of peripheral resistance and preload as well as ventricular function on the AoI, whereas Delta-MPI quantifies differential systolic and diastolic myocardial function only [22]. Other research groups have raised concerns regarding the ability of the ISI to accurately and specifically isolate relative ventricular contribution [23]. Theoretically, if cerebral vascular impedance were to decrease, a higher proportion of the LV stroke volume would be redistributed to the brain, reducing the influence that the LV has upon the AoI systolic component in comparison to the RV. Concomitantly, there would be an increase in right ventricular preload. Thus, it is unlikely that in conditions such as IUGR the ISI would selectively be quantifying only comparative ventricular contribution to $\mathrm{CO}$.

\section{Potential for Aol to Be Part of Clinical Practice}

Studies have suggested a role for AoI measurement in pathology; yet a clinical situation where evaluation of this anatomical landmark provides a clear benefit is still unclear. AoI waveforms have been explored in a number of pathologies: IUGR, twin-twin transfusion syndrome (TTTS), fetuses of diabetic mothers, congenital diaphragmatic hernia $(\mathrm{CDH})$, ventricular septal defect (VSD), coarctation of the aorta ( $\mathrm{CoA})$, and other congenital heart diseases (CHD). These are summarised in table 4 and outlined below.

\section{Aol in Extracardiac Functional Pathology}

\section{Intrauterine Growth Restriction}

IUGR complicates approximately $3-10 \%$ of all pregnancies [24], and may be characterised by 'brain sparing', where the fetus compensates for chronic hypoxia by redistributing blood flow to vital organs including the brain and myocardium, particularly in early-onset disease [25]. This haemodynamic compensation can cause sequential right cardiac failure, followed by left cardiac failure being observed just prior to intrauterine demise [26]. As there is no effective in utero therapy [27-30], obstetric management involves timing delivery before decompensated heart failure but preferably after sufficient fetal lung maturation to minimise neonatal complications [31]. In current clinical practice, fetal heart rate analysis, biophysical parameters, and ultrasound indices such as UA, MCA, and ductus venosus (DV) Doppler can only guide clinicians, as the usual sequence of recognised changes do not occur in all fetal demise cases [26, 32, 33]. Other Doppler indices or vessels of interest published in the literature in relation to IUGR monitoring include the cerebroplacental ratio [CPR, which combines two of the above parameters (MCA PI/UA PI)], MPI, hepatic artery, umbilical vein, E/A ratios, and outflow tracts [24, 26, 34-36].

The direction of oxygenated blood to the brachiocephalic circulation with uteroplacental insufficiency has led the AoI to be studied in IUGR fetuses [2]. Placental insufficiency causes a reduction in RV CO, while LV CO is usually preserved [37]. Alterations in the diastolic component of the AoI therefore reflect comparative impedance of the cerebral and peripheral vascular beds. To date most studies involving AoI Doppler have focused on diastole, attempting to assist in the timing of delivery of IUGR fetuses (table 4) [6, 8, 15, 17, 19, 26, 31, 38-51]. Reversed diastolic AoI flow suggests significant fetal hypoxic deterioration, usually occurring after the UA, MCA, and CPR Doppler parameters become abnormal, but preceding DV Doppler abnormalities by an average of 1 week $[6,17,31,39,40,44]$. In a fetal sheep model with stepwise compression of umbilical veins, as well as in a computerbased fetal circulation model, the appearance of net retrograde flow in the AoI physiologically demonstrates cerebral hypoxia despite local vasodilation and preservation of cerebral blood flow. This is due to poorly oxygenated preplacental blood coming from the RV contaminating the ascending aortic blood (coming from the LV) destined for the brain, resulting in a reduction in mean oxygen tension in the cerebral vascular bed [5255]. Additionally, these fetuses cannot shift their RV CO from the pulmonary circulation through the foramen ovale. IUGR fetuses that maintain antegrade AoI net blood flow increase the flow across the foramen ovale to ensure highly oxygenated blood flow reaches the coronary and cerebral vascular beds [49]. 
Table 4. Summary of previously published human fetal studies exploring the value of the AoI in cardiac and extracardiac pathology

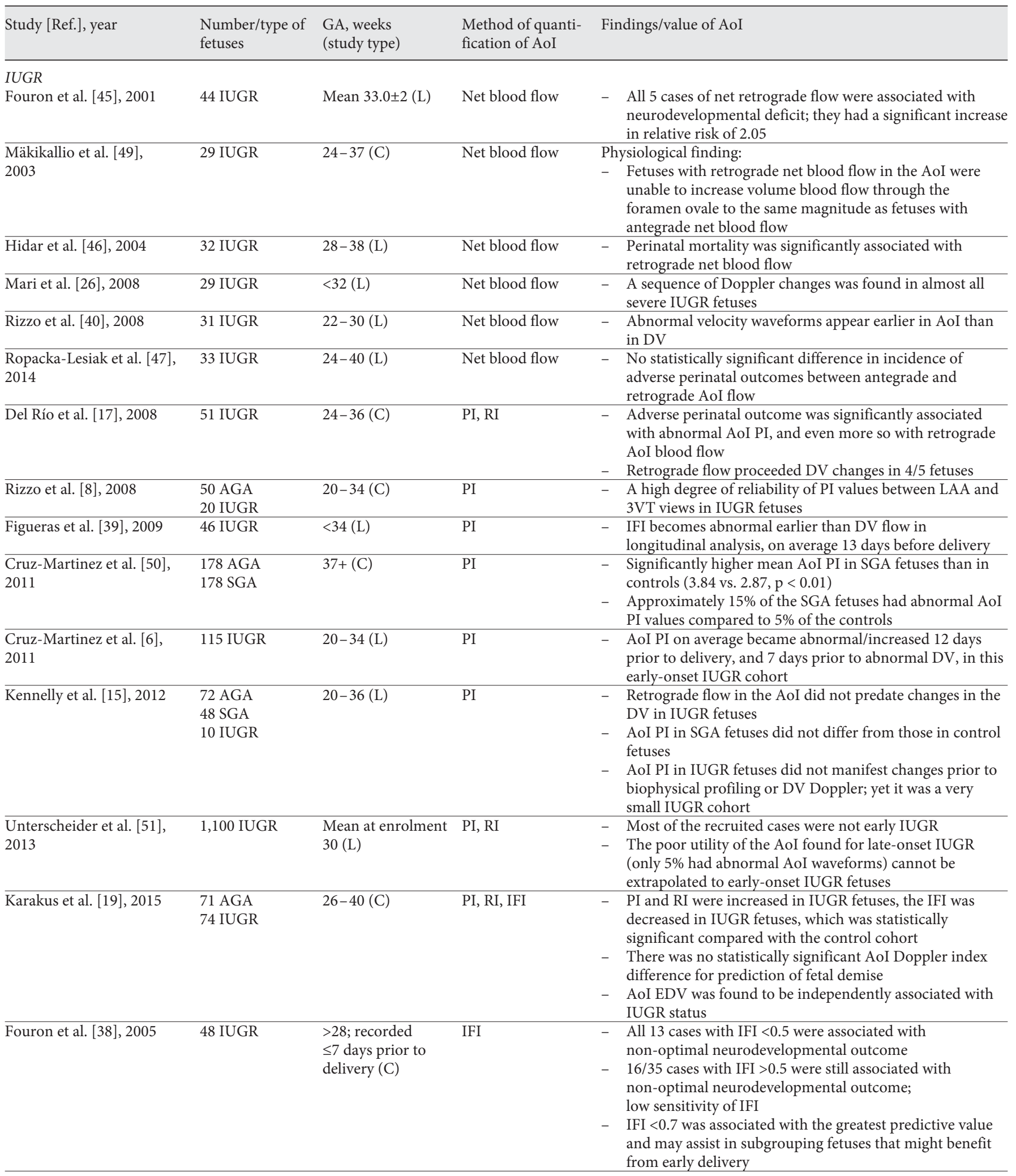


Table 4 (continued)

\begin{tabular}{|c|c|c|c|c|}
\hline Study [Ref.], year & $\begin{array}{l}\text { Number/type of } \\
\text { fetuses }\end{array}$ & $\begin{array}{l}\text { GA, weeks } \\
\text { (study type) }\end{array}$ & $\begin{array}{l}\text { Method of quanti- } \\
\text { fication of AoI }\end{array}$ & Findings/value of AoI \\
\hline $\begin{array}{l}\text { Hernández-Andrade et al. } \\
{[31], 2009}\end{array}$ & 97 IUGR & $24-34(C)$ & IFI & $\begin{array}{l}\text { - Multivariate analysis indicated that IFI does not add to the } \\
\text { prediction of perinatal death when used in combination } \\
\text { with DV flow } \\
\text { - AoI reversed diastolic flow suggests a deterioration in } \\
\text { cardiac function }\end{array}$ \\
\hline Crispi et al. [48], 2009 & $\begin{array}{l}120 \text { AGA } \\
62 \text { IUGR }\end{array}$ & $24-37(\mathrm{C})$ & IFI & $\begin{array}{l}\text { - All IUGR cases showed signs of cardiac dysfunction } \\
\text { compared with normal cases; no indication about what } \\
\text { percentage the IFI was abnormal in }\end{array}$ \\
\hline $\begin{array}{l}\text { Benavides-Serralde et al. } \\
{[43], 2011}\end{array}$ & $\begin{array}{l}33 \text { SGA } \\
57 \text { IUGR }\end{array}$ & $20-36(\mathrm{~L})$ & IFI & $\begin{array}{l}\text { - IFI along with DV PI and MPI showed the most consistent } \\
\text { changes of all Doppler parameters for haemodynamic } \\
\text { deterioration }\end{array}$ \\
\hline $\begin{array}{l}\text { Cruz-Lemini et al. [41], } \\
2012\end{array}$ & 157 IUGR & $26-37(C)$ & IFI & $\begin{array}{l}\text { - } \text { IFI was significantly associated with perinatal mortality } \\
\text { - } \quad \text { Decision tree analysis and multivariate models found a } \\
\text { lack of utility for IFI to predict perinatal mortality }\end{array}$ \\
\hline $\begin{array}{l}\text { Lecarpentier et al. [42], } \\
2013\end{array}$ & 109 IUGR & $24-40(\mathrm{~L})$ & IFI & $\begin{array}{l}\text { - IFI scores were significantly lower in those with ARED } \\
\text { flow in } 2 \text { UA compared to ARED in } 1 \text { UA }\end{array}$ \\
\hline $\begin{array}{l}\text { Abdelrazzaq et al. [44], } \\
2013\end{array}$ & 31 IUGR & $24-37(\mathrm{~L})$ & PI, RI, IFI & $\begin{array}{l}\text { - AoI PI and RI were significantly associated with perinatal } \\
\text { complications and fetal death } \\
\text { - } \quad \text { IFI was useful for detecting deterioration and adverse } \\
\text { perinatal outcomes before DV blood flow }\end{array}$ \\
\hline $\begin{array}{l}\text { Lulic Jurjevic et al. [56], } \\
2014\end{array}$ & 62 IUGR & $24-37(\mathrm{C})$ & ISI & $\begin{array}{l}\text { Abstract } \\
\text { - Systolic nadir started to be retrograde at } 26 \text { weeks in the } \\
\text { IUGR group, compared to } 31 \text { weeks in the control group } \\
\text { - Between } 29 \text { and } 32 \text { weeks, the ISI was significantly lower } \\
\text { in the IUGR group compared to the control group }\end{array}$ \\
\hline $\begin{array}{l}\text { Martin et al. [57], } \\
2015\end{array}$ & 113 IUGR & $24-34(?)$ & ISI & $\begin{array}{l}\text { Abstract } \\
\text { - No significant difference }(\mathrm{p}=0.054) \text { in ISI was found } \\
\text { between IUGR fetuses with normal DV function and those } \\
\text { with an abnormal DV profile or CPR }<1 \\
\text { - Nadir was dramatically different between these two groups }\end{array}$ \\
\hline \multicolumn{5}{|l|}{ Fetuses of diabetic mothers } \\
\hline Zielinsky et al. [21], 2011 & $\begin{array}{l}23 \text { controls } \\
50 \text { mothers } \\
\text { with diabetes }\end{array}$ & $25-39(\mathrm{C})$ & IFI & $\begin{array}{l}\text { - Fetuses of diabetic mothers with and without myocardial } \\
\text { hypertrophy had lower mean IFI values than control } \\
\text { fetuses }\end{array}$ \\
\hline
\end{tabular}

TTTS

Leduc et al. [60], 2014

\section{TTTS}

pregnancies

before laser

25 TTTS

pregnancies

after laser

Leduc et al. [59], 2015

43 TTTS

recipients before

laser

33 TTTS

recipients after

laser

Structural pathology

İlhan et al. [61], 2016

74 controls $\quad 29-36(\mathrm{C}) \quad$ IFI

$64 \mathrm{CHD}$
ISI

ISI $-\quad$ Recipient ISI was found to be of significant progn
value for intrauterine fetal demise preoperatively normal fetuses at the same GA
- Pre- and post-laser ISI values were similar to those of

- ISI values did not differ in cases of intrauterine fetal demise compared with surviving TTTS cases or controls

- IFI values in CHD fetuses were significantly lower than in controls; this included fetuses with ToF (13), AS (8), muscular VSD (10), AVSD (7), PS (3), ASD (1), CoA (1), hypoplastic left heart (4), bicuspid aorta (1), hypoplastic right heart (1), perimembranous VSD (1), truncus arteriosus (1), double-outlet right ventricle (1), and TGA (1)

- Study concluded that AoI Doppler profiles might increase the sensitivity of diagnosing CHD in those that are overlooked 
Table 4 (continued)

\begin{tabular}{|c|c|c|c|c|}
\hline Study [Ref.], year & $\begin{array}{l}\text { Number/type of } \\
\text { fetuses }\end{array}$ & $\begin{array}{l}\text { GA, weeks } \\
\text { (study type) }\end{array}$ & $\begin{array}{l}\text { Method of quanti- } \\
\text { fication of AoI }\end{array}$ & Findings/value of AoI \\
\hline Matsui et al. [62], 2008 & $\begin{array}{l}200 \text { controls } \\
44 \text { fetuses with } \\
\text { suspected CoA }\end{array}$ & $15-39(\mathrm{~L})$ & $\begin{array}{l}\text { Isthmus diameter, } \\
\text { Z-score, } \\
\text { net blood flow }\end{array}$ & $\begin{array}{l}\text { - Isthmus Z-scores are a sensitive indicator of fetal CoA } \\
\text { - } \quad \text { Qualitative assessment of AoI flow disturbance increased } \\
\text { the odds ratio of true CoA versus arch hypoplasia 16-fold }\end{array}$ \\
\hline Jowett et al. [63], 2012 & $\begin{array}{l}37 \text { fetuses with } \\
\text { suspected CoA }\end{array}$ & $16-37(\mathrm{~L})$ & $\begin{array}{l}\text { Isthmus diameter, } \\
\text { Z-score, } \\
\text { net blood flow }\end{array}$ & $\begin{array}{l}\text { AoI incorporation into an assessment of fetuses with } \\
\text { suspected CoA resulted in a better diagnostic prediction } \\
\text { regarding which cases would require neonatal surgery }\end{array}$ \\
\hline $\begin{array}{l}\text { Chabaneix et al. [64], } \\
2015\end{array}$ & $\begin{array}{l}104 \text { controls } \\
24 \text { fetuses with } \\
\text { isolated VSD }\end{array}$ & $18-38(\mathrm{C})$ & ISI & $\begin{array}{l}\text { Abstract } \\
\text { - From } 18 \text { to } 27 \text { weeks, there was no statistical difference } \\
\text { between groups } \\
\text { - } \quad \text { Beyond } 28 \text { weeks, the ISI values of the } 15 \text { fetuses with } \\
\text { restrictive VSD were similar to those of the controls; yet, } \\
\text { in the } 9 \text { fetuses with large VSD, the ISI values remained } \\
\text { statistically higher than in the two previous groups }\end{array}$ \\
\hline $\begin{array}{l}\text { Codsi et al. [65], } \\
2012\end{array}$ & $\begin{array}{l}36 \text { fetuses with } \\
\mathrm{CDH}\end{array}$ & $20-35(\mathrm{~L})$ & ISI & $\begin{array}{l}\text { Abstract } \\
\text { - } 9 \text { fetuses did not survive, all of whom had severe } \\
\text { pulmonary artery hypertension; these fetuses showed a } \\
\text { failed decrease in ISI values to keep within normal range } \\
\text { at } 35 \text { weeks, unlike the surviving fetuses with CDH } \\
\text { - Difficulty in obtaining Doppler at } 35 \text { weeks in all fetuses, } \\
\text { meaning the presented results are not clear }\end{array}$ \\
\hline
\end{tabular}

$\mathrm{L}=$ Longitudinal $\mathrm{C}=$ cross-sectional; $\mathrm{GA}=$ gestational age; $\mathrm{AGA}=$ appropriate for gestational age; $\mathrm{SGA}=$ small for gestational age; $\mathrm{ARED}=$ absent or reverse end-diastolic; ToF = tetralogy of Fallot; AS = aortic stenosis; PS = pulmonary stenosis; ASD = atrial septal defect; AVSD = atrioventricular septal defect; TGA = transposition of great arteries.

This has led to questioning whether the cerebral hypoxia detected by reverse net diastolic AoI blood flow causes cerebral damage. Retrograde diastolic AoI waveforms have been shown to be associated with poor neurodevelopmental outcome [38, 45], although despite being highly specific, sensitivity was low [38]. Similarly, it was suggested abnormal AoI PI and/or IFI could predict adverse perinatal outcomes including perinatal mortality in early-onset IUGR and may be a complementary measure in timing delivery, although gestational age at delivery was a significant cofounding factor in these studies $[17,39,40,44]$. A prospective multicentre study of 157 early-onset IUGR fetuses aimed to validate these results. While abnormal AoI IFI was significantly associated with perinatal mortality, on decision tree analysis and multivariate models it was not clinically useful for predicting mortality, suggesting it is instead a surrogate marker of brain sparing [41]. The large PORTO study also investigated the sensitivity and clinical utility of AoI PI and RI (among other Doppler measures) in monitoring small for gestational age fetuses and did not find the AoI to be of benefit. However, a sizeable portion of their cases were of late-onset IUGR. Hence their findings cannot be applied to early-onset cases, and the AoI may yet prove to have a clinical role in the early-onset subgroup [51].
AoI IFI, PI, and RI are therefore still largely research tools for the assessment and management of placental insufficiency and are yet to be incorporated into clinical practice. Studies thus far have identified the specificity of AoI diastolic indices to detect IUGR and have made some significant research associations with neurological sequelae; yet the AoI lacks the sensitivity to detect all IUGR fetuses at risk [38, 41, 47, 50]. Until longitudinal follow-up studies or randomised study protocols indicate a benefit from AoI use in clinical practice, it will continue to remain a research tool. As AoI ISI is a new index, only two abstracts exploring the ISI in IUGR fetuses exist in the literature. One study found that the ISI was significantly lower in 62 IUGR fetuses compared to controls until 32 weeks' gestation. It also found that the systolic nadir of the AoI became retrograde at 26 weeks in IUGR fetuses compared to 31 weeks in their normal population [56]; yet the established ISI normal range study found that the systolic nadir appeared at 28 weeks' gestation in a normal population [14]. The other abstract on 113 IUGR fetuses also found statistically different systolic nadir values when comparing IUGR fetuses with balanced haemodynamic status to those with poor circulatory status ( $\mathrm{CPR}<1$, or absent or reversed $\mathrm{A}$ wave in the DV profile) [57].
90 


\section{Diabetes}

Maternal diabetes may cause hypertrophic cardiomyopathy with thickening of the interventricular septum and obstruction of outflow tracts in about a quarter of affected pregnancies $[21,53]$. Only one study investigated the AoI in fetuses of diabetic mothers, where lower IFI values were observed. The authors proposed that LV diastolic dysfunction could be detected using the AoI before the appearance of myocardial hypertrophy [21]. However, other indices such as ventricular inflow patterns, atrial shortening fraction, and isovolumetric relaxation time have also been found to be abnormal in diabetic fetuses without myocardial hypertrophy [53].

\section{Twin-Twin Transfusion Syndrome}

TTTS occurs almost exclusively in the monochorionic diamniotic subgroup of twins via vascular anastomoses on the placental surface [58]. Net volume shifts of blood result in a hypovolaemic donor twin at risk of fetal growth restriction, hypertension, and hypoxia and a hypervolaemic recipient twin at risk of hypertrophic cardiomyopathy and RV dysfunction followed by LV dysfunction [3, 58]. Only two observational abstracts have been published in the literature exploring the AoI in TTTS fetuses, both of which explored the ISI. Only one of these studies found the ISI to be a statistically significant predictor of cardiac strain and intrauterine fetal demise in 43 TTTS recipient fetuses preoperatively [59]. The other study of 29 TTTS pregnancies before and 25 TTTS pregnancies after laser photocoagulation found no prognostic value or difference in ISI values compared to controls or between surviving and non-surviving fetuses [60]. Overall, the AoI has not been shown to be clinically useful in the evaluation of TTTS fetuses, and more widely researched and accepted parameters are available, such as tricuspid regurgitation, DV, ventricular wall hypertrophy, or cardiomegaly [58].

\section{Aol in Structural Pathology}

The AoI has been proposed to be a useful indicator of structural CHD, in particular CoA, aortic stenosis, VSD, and transposition of the great arteries. Only one casecontrol study explored the IFI in CHD [61], finding a statistical difference in the overall sample of 64 fetuses with various types of $\mathrm{CHD}$. However, after subgrouping by anomaly, the limited sample size restricted the significance of this finding. The largest subgroups included tetralogy of Fallot (13 fetuses) and muscular VSD $(n=10)$, for which statistically lower IFI values were seen [61]; the study concluded that AoI Doppler profiles might increase the sensitivity of CHD diagnosis.

There are limited studies exploring the AoI in pathologies such as CoA and VSD; however, the preliminary findings are promising. AoI diameter measurement and qualitative assessment of diastolic flow have been found to be accurate indicators in the antenatal diagnosis of CoA $[62,63]$; yet no studies have explored how quantitative Doppler parameters behave in such pathology. As regards VSD, one published abstract on 24 fetuses with VSD showed the ISI to be useful to predict large VSD with significant postnatal impact. In such cases, the ISI remained statistically higher beyond 28 weeks' gestation without the normal RV preponderance being observed secondary to inappropriate ventricular mixing [64]. While no studies to date have explored AoI flow in fetal aortic stenosis, theoretically its use has potential given the significantly decreased comparative LV output compared to RV output in such pathologies.

In fetuses with $\mathrm{CDH}$, the left heart is often underdeveloped. The AoI has only been explored in one study in such pathology. The abstract study found normal ISI curves throughout gestation in $27 \mathrm{CDH}$ survivors; yet in the 9 non-survivors, the ISI values did not show the normal decrease in late gestation ( $>35$ weeks) [65]. However, obtaining AoI views was not possible in all fetuses in late gestation due to technical difficulties, so these results are of little clinical value [65].

\section{Conclusion}

The AoI is a fascinating arterial watershed that offers significant potential to further improve our understanding of fetal haemodynamic physiology. It produces relatively complex waveforms that are constructed from both LV and RV contributions to CO, along with impedance in multiple vascular beds. The systolic component is determined in the main part by ventricular systolic ejection, and the diastolic by vascular impedance. Various intracardiac and extracardiac pathologies may alter these waveforms, and a number of indices have been derived to capture their significance in this watershed, including the PI, RI, IFI, and ISI. Despite these indices, more physiological studies are required to understand its flow velocity waveform. There have been many promising preliminary studies in pathological conditions, though these have not yet been translated to any clear clinical utility. A 
clear reason for this is the multifactorial origin of the waveform and the need to disentangle these different causes. Ultimately, the AoI may prove to be a useful tool to assess the severity of fetal cardiac and haemodynamic compromise in functional (e.g. IUGR and TTTS) or structural (e.g. VSD, CoA, and CDH) pathological conditions, and research is underway in a number of centres towards this goal.

\section{References}

1 Fouron JC: The unrecognized physiological and clinical significance of the fetal aortic isthmus. Ultrasound Obstet Gynecol 2003;22: 441-447.

2 Acharya G: Technical aspects of aortic isthmus Doppler velocimetry in human fetuses. Ultrasound Obstet Gynecol 2009;33:628-633.

3 Rychik J: Fetal cardiovascular physiology. Pediatr Cardiol 2004;25:201-209.

4 Kiserud T: Physiology of the fetal circulation. Semin Fetal Neonatal Med 2005;10:493-503.

-5 Del Río M, Martínez JM, Figueras F, Bennasar M, Palacio M, Gómez O, Coll O, Puerto B, Cararach V: Doppler assessment of fetal aortic isthmus blood flow in two different sonographic planes during the second half of gestation. Ultrasound Obstet Gynecol 2005;26: 170-174.

- 6 Cruz-Martinez R, Figueras F, BenavidesSerralde A, Crispi F, Hernández-Andrade E, Gratacós E: Sequence of changes in myocardial performance index in relation to aortic isthmus and ductus venosus Doppler in fetuses with early-onset intrauterine growth restriction. Ultrasound Obstet Gynecol 2011; 38:179-184.

7 Yagel S, Cohen S, Achiron R: Examination of the fetal heart by five short-axis views: a proposed screening method for comprehensive cardiac evaluation. Ultrasound Obstet Gynecol 2001;17:367-369.

8 Rizzo G, Capponi A, Vendola M, Pietrolucci ME, Arduini D: Use of the 3-vessel view to record Doppler velocity waveforms from the aortic isthmus in normally grown and growth-restricted fetuses: comparison with the long aortic arch view. J Ultrasound Med 2008;27:1617-1622.

\9 Gámez F, Rodríguez MJ, Tenías JM, García J, Pintado P, Martín R, Pérez R, Ortiz-Quintana L, De León-Luis J: Reference ranges for the pulsatility index of the fetal aortic isthmus in singleton and twin pregnancies. J Ultrasound Med 2015;34:577-584.

$\checkmark 10$ Fouron JC, Siles A, Montanari L, Morin L, Ville Y, Mivelaz Y, Proulx F, Bureau N, Bigras JL, Brassard M: Feasibility and reliability of Doppler flow recordings in the fetal aortic isthmus: a multicenter evaluation. Ultrasound Obstet Gynecol 2009;33:690-693.

11 Del Río M, Martínez JM, Figueras F, López M, Palacio M, Gómez O, Coll O, Puerto B: Reference ranges for Doppler parameters of the fetal aortic isthmus during the second half of pregnancy. Ultrasound Obstet Gynecol 2006; 28:71-76.
2 Acharya G, Pavlovic M, Ewing L, Nollmann D, Leshko J, Huhta JC: Comparison between pulsed-wave Doppler- and tissue Dopplerderived Tei indices in fetuses with and without congenital heart disease. Ultrasound $\mathrm{Ob}-$ stet Gynecol 2008;31:406-411.

13 Welsh AW, Meriki N, Henry A: The 'DeltaMPI': a new measure for unilateral fetal myocardial strain and its normal gestational range (abstract OP27.04). Ultrasound Obstet Gynecol 2012;40:136.

14 Chabaneix J, Fouron JC, Sosa-Olavarria A, Gendron R, Dahdah N, Berger A, Brisebois S: Profiling left and right ventricular proportional output during fetal life with a novel systolic index in the aortic isthmus. Ultrasound Obstet Gynecol 2014;44:176-181.

15 Kennelly MM, Farah N, Hogan J, Reilly A, Turner MJ, Stuart B: Longitudinal study of aortic isthmus Doppler in appropriately grown and small-for-gestational-age fetuses with normal and abnormal umbilical artery Doppler. Ultrasound Obstet Gynecol 2012; 39:414-420.

16 Vimpeli T, Huhtala H, Wilsgaard T, Acharya G: Fetal aortic isthmus blood flow and the fraction of cardiac output distributed to the upper body and brain at 11-20 weeks of gestation. Ultrasound Obstet Gynecol 2009;33: 538-544.

17 Del Río M, Martínez JM, Figueras F, Bennasar M, Olivella A, Palacio M, Coll O, Puerto B, Gratacós E: Doppler assessment of the aortic isthmus and perinatal outcome in preterm fetuses with severe intrauterine growth restriction. Ultrasound Obstet Gynecol 2008;31:4147.

18 Thanasuan S, Phithakwatchara N, Nawapan $\mathrm{K}$ : Reference values for fetal aortic isthmus blood flow parameters at 24 to 38 weeks' gestation. Prenat Diagn 2014;34:241-245.

$>19$ Karakus R, Ozgu-Erdinc AS, Esercan A, Dogan MM: Doppler assessment of the aortic isthmus in intrauterine growth-restricted fetuses. Ultrasound Q 2015;31:170-174.

20 Ruskamp J, Fouron JC, Gosselin J, Raboisson MJ, Infante-Rivard C, Proulx F: Reference values for an index of fetal aortic isthmus blood flow during the second half of pregnancy. Ultrasound Obstet Gynecol 2003;21:441444.

21 Zielinsky P, Frajndlich R, Nicoloso LH, Manica JLL, Piccoli AL Jr, de Morais MR, Bender L, Silva J, Pizzato P, Naujorks A: Aortic isthmus blood flow in fetuses of diabetic mothers. Prenat Diagn 2011;31:1176-1180.
22 Tynan D, Henry A, Alphonse J, Welsh A: Correlation between the delta-myocardial performance index and aortic isthmus systolic index as markers of unilateral cardiac strain (abstract P06.05). Ultrasound Obstet Gynecol 2015;46:140-140.

23 Rychik J: Re: Profiling left and right ventricular proportional output during fetal life with a novel systolic index in the aortic isthmus. J Chabaneix, JC Fouron, A Sosa-Olavarria, R Gendron, N Dahdah, A Berger and S Brisebois. Ultrasound Obstet Gynecol 2014;44: 176-181. Ultrasound Obstet Gynecol 2014; 44:136.

24 Baschat AA, Gembruch U, Weiner CP, Harman CR: Qualitative venous Doppler waveform analysis improves prediction of critical perinatal outcomes in premature growth-restricted fetuses. Ultrasound Obstet Gynecol 2003;22:240-245.

25 Peebles DM: Fetal consequences of chronic substrate deprivation. Semin Fetal Neonatal Med 2004;9:379-386.

26 Mari G, Hanif F, Kruger M: Sequence of cardiovascular changes in IUGR in pregnancies with and without preeclampsia. Prenat Diagn 2008;28:377-383

27 Say L, Gülmezoglu A, Hofmeyr GJ: Maternal oxygen administration for suspected impaired fetal growth. Cochrane Database Syst Rev 2003;1:CD000137.

28 Say L, Gülmezoglu AM, Hofmeyr GJ: Maternal nutrient supplementation for suspected impaired fetal growth. Cochrane Database Syst Rev 2003;1:CD000148.

29 Gülmezoglu AM, Hofmeyr GJ: Betamimetics for suspected impaired fetal growth. Cochrane Database Syst Rev 2001;4:CD000036.

30 Gülmezoglu AM, Hofmeyr GJ: Plasma volume expansion for suspected impaired fetal growth. Cochrane Database Syst Rev 2000; 2:CD000167.

31 Hernández-Andrade E, Crispi F, BenavidesSerralde JA, Plasencia W, Diesel HF, Eixarch E, Acosta-Rojas R, Figueras F, Nicolaides K, Gratacós E: Contribution of the myocardial performance index and aortic isthmus blood flow index to predicting mortality in preterm growth-restricted fetuses. Ultrasound Obstet Gynecol 2009;34:430-436.

-32 Turan S, Miller J, Baschat AA: Integrated testing and management in fetal growth restriction. Semin Perinatol 2008;32:194-200.

33 Figueras F, Gratacós E: Stage-based approach to the management of fetal growth restriction. Prenat Diagn 2014;34:655-659. 
-34 Hernández-Andrade E, Benavides-Serralde JA, Cruz-Martinez R, Welsh A, MancillaRamirez J: Evaluation of conventional Doppler fetal cardiac function parameters: E/A ratios, outflow tracts, and myocardial performance index. Fetal Diagn Ther 2012;32:2229.

- 35 Warshak CR, Masters H, Regan J, DeFranco E: Doppler for growth restriction: the association between the cerebroplacental ratio and a reduced interval to delivery. J Perinatol 2015; 35:332-337.

- 36 Ebbing C, Rasmussen S, Kiserud T: Middle cerebral artery blood flow velocities and pulsatility index and the cerebroplacental pulsatility ratio: longitudinal reference ranges and terms for serial measurements. Ultrasound Obstet Gynecol 2007;30:287-296.

- 37 al-Ghazali W, Chita SK, Chapman MG, Allan LD: Evidence of redistribution of cardiac output in asymmetrical growth retardation. $\mathrm{Br} \mathrm{J}$ Obstet Gynaecol 1989;96:697-704.

- 38 Fouron J-C, Gosselin J, Raboisson M-J, Lamoureux J, Tison C-A, Fouron C, Hudon $\mathrm{L}$ : The relationship between an aortic isthmus blood flow velocity index and the postnatal neurodevelopmental status of fetuses with placental circulatory insufficiency. Am J Obstet Gynecol 2005; 192:497-503.

- 39 Figueras F, Benavides A, Del Río M, Crispi F, Eixarch E, Martinez JM, Hernández-Andrade E, Gratacós E: Monitoring of fetuses with intrauterine growth restriction: longitudinal changes in ductus venosus and aortic isthmus flow. Ultrasound Obstet Gynecol 2009;33:3943.

-40 Rizzo G, Capponi A, Vendola M, Pietrolucci ME, Arduini D: Relationship between aortic isthmus and ductus venosus velocity waveforms in severe growth restricted fetuses. Prenat Diagn 2008;28:1042-1047.

-41 Cruz-Lemini M, Crispi F, Van Mieghem T, Pedraza D, Cruz-Martínez R, Acosta-Rojas R, Figueras F, Parra-Cordero M, Deprest J, Gratacós E: Risk of perinatal death in earlyonset intrauterine growth restriction according to gestational age and cardiovascular Doppler indices: a multicenter study. Fetal Diagn Ther 2012;32:116-122.

-42 Lecarpentier E, Cordier AG, Proulx F, Fouron JC, Gitz L, Grange G, Benachi A, Tsatsaris V: Hemodynamic impact of absent or reverse end-diastolic flow in the two umbilical arteries in growth-restricted fetuses. PLoS One 2013;8:e81160.

-43 Benavides-Serralde A, Scheier M, Cruz-Martinez R, Crispi F, Figueras F, Gratacós E, Hernández-Andrade E: Changes in central and peripheral circulation in intrauterine growth-restricted fetuses at different stages of umbilical artery flow deterioration: new fetal cardiac and brain parameters. Gynecol Obstet Invest 2011;71:274-280.
44 Abdelrazzaq K, Yeniel AÖ, Ergenoglu AM, Yildirim N, Akercan F, Karadadaş N: Fetal aortic isthmus Doppler measurements for prediction of perinatal morbidity and mortality associated with fetal growth restriction. Acta Obstet Gynecol Scand 2013;92:656-661.

-45 Fouron J-C, Gosselin J, Amiel-Tison C, Infante-Rivard C, Fouron C, Skoll A, Veilleux A: Correlation between prenatal velocity waveforms in the aortic isthmus and neurodevelopmental outcome between the ages of 2 and 4 years. Am J Obstet Gynecol 2001;184:630636.

46 Hidar S, Zaafouri R, Bouguizane S, Chaieb A, Jerbi M, Bibi M, Khairi H: Prognostic value of fetal aortic isthmus Doppler waveform in intrauterine growth retardation: prospective longitudinal study. J Gynecol Obstet Biol Reprod (Paris) 2004;33:745-752.

47 Ropacka-Lesiak M, Swider-Musielak J, Wójcicka M, Hamid A, Breborowicz GH: Retrograde diastolic blood flow in the aortic isthmus is not a simple marker of abnormal fetal outcome in pregnancy complicated by IUGR - a pilot study. Ginekol Pol 2014;85: 509-515.

48 Crispi F, Comas M, Hernández-Andrade E, Eixarch E, Gómez O, Figueras F, Gratacós E: Does pre-eclampsia influence fetal cardiovascular function in early-onset intrauterine growth restriction? Ultrasound Obstet Gynecol 2009;34:660-665.

49 Mäkikallio K, Jouppila P, Räsänen J: Retrograde aortic isthmus net blood flow and human fetal cardiac function in placental insufficiency. Ultrasound Obstet Gynecol 2003;22: 351-357.

50 Cruz-Martinez R, Figueras F, Hernández-Andrade E, Oros D, Gratacós E: Changes in myocardial performance index and aortic isthmus and ductus venosus Doppler in term, smallfor-gestational age fetuses with normal umbilical artery pulsatility index. Ultrasound Obstet Gynecol 2011;38:400-405.

51 Unterscheider J, Daly S, Geary MP, Kennelly MM, McAuliffe FM, O’Donoghue K, Hunter A, Morrison JJ, Burke G, Dicker P, Tully EC: Predictable progressive Doppler deterioration in IUGR: does it really exist? Am J Obstet Gynecol 2013;209:539.e1-7.

52 Fouron J-C, Skoll A, Sonesson S-E, Pfizenmaier M, Jaeggi E, Lessard M: Relationship between flow through the fetal aortic isthmus and cerebral oxygenation during acute placental circulatory insufficiency in ovine fetuses. Am J Obstet Gynecol 1999;181:1102-1107.

53 Van Mieghem T, Hodges R, Jaeggi E, Ryan G: Functional echocardiography in the fetus with non-cardiac disease. Prenat Diagn 2014; 34:23-32.

54 Garcia-Canadilla P, Rudenick PA, Crispi F, Cruz-Lemini M, Palau G, Camara O, Gratacós E, Bijens BH: A computational model of the fetal circulation to quantify blood redistribution in intrauterine growth restriction. PLoS Comput Biol 2014;10:e1003667.
55 Bonnin P, Fouron J, Teyssier G, Sonesson S, Skoll A: Quantitative assessment of circulatory changes in the fetal aortic isthmus during progressive increase of resistance to umbilical blood flow. Circulation 1993;88:216-222.

56 Lulic Jurjevic R, Fouron J, Gendron R, Audibert F, Bujold E, Dubé J, Jaeggi E, Klam S, Mayer C: Indirect assessment of central blood flow dynamics and cerebral oxygenation in fetuses with placental circulatory insufficiency (abstract OP25.04). Ultrasound Obstet Gynecol 2014;44:142.

57 Martin O, Chabaneix J, Proulx F, Cordier A, Coatleven F, Dallay D, Thambo J, Benachi A: IUGR fetuses and systolic aortic isthmus flow Doppler: values of the isthmic systolic index (ISI) (abstract P08.05). Ultrasound Obstet Gynecol 2015;46:148.

58 Bebbington M: Twin-to-twin transfusion syndrome: current understanding of pathophysiology, in-utero therapy and impact for future development. Semin Fetal Neonatal Med 2010;15:15-20.

59 Leduc F, Delabaere A, Gendron R, Reboul Q, Fuchs F, Wavrant S, Dubé J, Fouron JC, Audibert F: Aortic isthmus predicts neonatal outcome in twin-twin transfusion syndrome treated by laser coagulation (abstract OC18.04). Ultrasound Obstet Gynecol 2015; 46:38-39.

-60 Leduc F, Fuchs F, Gendron R, Fouron J, Audibert F: Aortic isthmus and umbilical artery Doppler for the prediction of intrauterine demise after laser photocoagulation in twintwin transfusion syndrome (abstract OC26.05). Ultrasound Obstet Gynecol 2014; 44:61.

61 İlhan G, İyibozkurt AC, Kalelioğlu HI, İbrahimoğlu L, Zebitay AG, Eken MK, Karasu AF: Effects of fetal cardiac anomalies on ductus venosus and aortic isthmus Doppler profiles. Arch Gynecol Obstet 2016;293:345-350.

-62 Matsui H, Mellander M, Roughton M, Jicinska H, Gardiner HM: Morphological and physiological predictors of fetal aortic coarctation. Circulation 2008;118:1793-1801.

63 Jowett V, Aparicio P, Santhakumaran S, Seale A, Jicinska H, Gardiner H: Sonographic predictors of surgery in fetal coarctation of the aorta. Ultrasound Obstet Gynecol 2012;40: 47-54.

64 Chabaneix J, Fouron J, Dahdah N: 0564: Can systolic Doppler velocimetry of fetal aortic isthmus help predicting post-natal clinical impact of ventricular septal defects? Arch Cardiovasc Dis Suppl 2015;7:98-99.

65 Codsi E, Wavrant S, Marty T, Duperron L, Dubé J, Audibert F, Fouron J: Prognostic value of the isthmic systolic index (ISI) in fetuses with congenital diaphragmatic hernia (abstract OC07.08). Ultrasound Obstet Gynecol 2012;40:15. 